\title{
IPPF(International Planned Parenthood Federation) 공여국 회의 결과
}

국제적십자사에 이어 세계 두 번째 규모의 국제 $\mathrm{NGO}$ 이자 가족계획 및 성생식보건 분야 세계 최대 국제 NGO인 IPPF는 2008.1.28 29간 런던에서 IPPF 공여국 회의를 개최하였다. 동 공여국 회의에 서 '존스 홉킨스 블룸버그 공중보건 스쿨'의 Duff G.Gillespie 박사는 우리나라의 가족계획사업을 민 관 통합 보건 시스템의 최우수 사례로 소개 하는 등 회의 참석자들이 우리나라의 개발경험에 대하여 높이 평가하였다. 과거 우리나라는 우리의 가족계획사업에 IPPF로부터 많은 지원을 받았으나 이제는 $\mathrm{ODA}$ 규모를 지속적으로 증대함으로써 IPPF와 공동사업을 펼쳐 나가고 있다. 우리는 ODA 사업 수 행에 있어 성생식보건 전문 기관인 IPPF의 경험과 지식, 그리고 우리나라의 민관 통합 보건시스템의 개발경험을 널리 활용할 수 있을 것이다. 〔정리 : 정책연구실〕

\section{I . IPPF 공여국 및 기관간 협의회}

1. Jacqueline Sharpe IPPF 회장의 환영사 : IPPF 및 회원의 거버넌스 강화를 위한 3 대 전략

- Jacqueline 회장은 2007년 IPPF의 활동을 성 공적으로 이끌어준 회원 및 임원진, 관련 활동 가들의 노력에 사의를 표하였으며, IPPF 집행 이사회(Governing Council)가 회원 및 IPPF 의 Good Governance를 위해 채택한 다음 세
가지 전략을 설명함

(1) IPPF Code of Good Governance 개발

- IPPF의 성과 사례를 구성하는 7가지 기 준(code)을 개발하였으며, 이 기준이 향후 $\mathrm{IPPF}$ 와 협회의 활동 지침이 되어 협회의 관리체계를 강화할 수 있다고 설명

(2) Volunteer(외부 임원진 및 관련 활동가)에 대한 IPPF 정책 변화

- 새로운 활동가들을 확보하고 현재 활동하 
고 있는 활동가들에게는 새로운 기회, 정 보, 교육을 제공하여 책임의식과 리더쉽 을 형성시킬 수 있도록함

(3) 모범 활동가들에 대한 상 수여

- IPPF 집행이사회가 성생식보건 권리 (SRHR : Sexual and Reproductive Health Rights)에 괄목할만한 기여를 한 협회 및 활동가들에 대해 상 수여

\section{2. $2006 / 2007$ 년 리포트}

\section{: Gill Greer 사무총장}

\section{: 아프리카 사업에 초점, 성권리 개념의 중요성, 시민사회의 역할}

- 사무총장은 2008년에는 아프리카에 초점을 두 고 사업을 추진할 것이며, 아프리카지역에서의 성생식보건 서비스 강화야말로 국제인구개발 회의(ICPD) 아젠다, MDGs, 마푸토 행동계획 을 달성하기 위해 필수적이라 설명함

- 사회적으로 가장 소외된 계층에 대한 서비스 확대와 우간다 난민 증가에 따른 사업을 추 진할 것이며, 모성사망률을 감소시키는 가장 중요한 사업 중 하나인 가족계획사업도 지속 적으로 추진할 것임을 언급함

- 또한 IPPF가 우선순위를 두고 있는 $5 \mathrm{~A}$ (1) safe abortion (2) HIV/AIDS (3) Access (4)
Adolescents (5) Advocacy)가 MDGs 목표 달성 및 빈곤퇴치를 위해 아주 중요하다는 것을 재확 인하고, 이에 대한 서비스 제공 강화, 가족계획, 생식보건, HIV/AIDS가 통합된 사업 추진, 그 리고 청소년들에 대한 지원 강화를 강조함

- 무엇보다 여성의 교육 기회 확대, 성적 자기 결 정권 강화 등이 가족계획, HIV/AIDS 방지 그 리고 빈곤퇴치와 밀접한 연관이 있다고 설명하 면서 인권 차원에서 성적 권리(Sexual Rights) 를 강조하였으며, 이를 위한 통합적 Sexuality 교육 프레임워크 개발, 성권리장전(Bill of Sexual Rights) 마련을 위한 회원들 간의 협의 와 의견 조율 등이 지속적으로 이루어지고 있 음을 설명함

- 또한, 회원심사(Accreditation) 과정을 통해 말 라위와 에콰도르가 신규 회원이 되었으며, 남 남협력(South-south networking)과 파트너 쉽을 강화해 갈 것을 강조함

- 아울러 지속적인 Advocacy 활동의 중요성을 강조하였으며, 그 성공사례로 2007.4월 세계 은행 보건 · 영양 - 인구정책에서 가족계획의 중요성이 평가 절하될 위기에 처하였으나, $\mathrm{IPPF}$ 및 성생식보건 관계자들의 지속적인 Advocacy 활동을 통해 관련 내용이 세계은행 전략에 유지될 수 있었던 활동을 이야기함

- 또한 생식보건 서비스가 국가 예산, 국가 빈곤 
감소전략, $\mathrm{MDGs}$ 달성 전략 등에 통합되어 전 달될 수 있도록 국가의 주인의식 제고 및 이를 위한 시민사회의 역할이 중요함을 강조함

\section{3. 재정보고}

- $2006 \mathrm{IPPF}$ 연맹 회원국들의 재정 총액은 272.7 백만불이며, IPPF 회원들의 평균 재정구 성은 국제사회의 지원금이 $12 \%, \mathrm{IPPF}$ 를 통한 지원금 $23 \%$, 지역수입 $65 \%$ 로 구성되어, 장기 적 관점에서 지속가능성을 확보하고 있는 것으 로 평가됨

- 특히 2006년 아프리카지역 회원들의 재정은 국제지원 $30 \%, \mathrm{IPPF}$ 지원 $11 \%$, 국내조달 $14 \%$ 로 형성되어, 서반구지역이 각각 $10 \%, 11 \%$, $79 \%$ 의 비율을 보이고 있는 것과 크게 대조됨.

- 2006년 IPPF를 통해 회원들이 받은 지원금은 96.4 백만 미불이며, 이 중 비제한적기금 (Unristricted fund)이 85\%, 특정목적에 쓰이 는 제한적기금(Restricted fund)은 $15 \%$ 를 차 지하고 있음

- 2007년 각국 정부 및 재단의 Unristricted 기 금은 총 76.7 백만 미불로, 주요 공여국은 영국 (19\%), 스웨덴(19\%), 일본(15\%), 덴마크(10\%), 노르웨이( $9 \%)$ 등 순임

- 2006년 주요 Restricted 기금은 EC(3.575백
만불), 빌게이츠멜린다재단(1.255백만불), 독 일정부(775천불), 일본정부의 HIV/AIDS 신탁 기금(1.002백만불), UNFPA(3.228백만불), UNAIDS(1.098백만불) 등으로 이루어짐

- 2008년 IPPF 예산은 Unristricted 기금이 74.9 백만불로 $6.8 \%$ 증가하였으며, Restricted 기금 역시 'Safe abortion action fund'로 인해 증가할 것으로 예상됨

\section{4. 소외그룹의 수요 충족과 2006 Global Indicators의 시사점}

- Global indicator(GI)는 IPPF 협회에서 실시 하는 사업의 모니터링 및 평가를 위한 것으로 $\mathrm{IPPF}$ 는 2006년 global survey (22개 지표)와 온라인 통계 모듈(8개 지표)을 제출하였으며, 이 지표를 2007 년도 사업에 적용하여 심도 검 토하였음

- 검토 결과, 협회들의 사업이 소외계층 및 사회 적으로 배제된 사람들의 수요를 충족시키는 방 향으로 이루어지고 있다는 것이 증명되었으며, UNDP 인간개발지수와 빈곤상황 기준 대비 최 고 지원 필요 지역에 IPPF 사업의 대부분이 집 중되어 있음을 확인하였음

- 이는 또한 공여된 재원 배분의 효율성을 높일 것으로 기대되어짐 


\section{Bill of Sexual Right(성권리장전) : 협의와 조율을 위한 다각적 접근}

- 성권리(Sexual Rights)는 개인의 성행동, 성적 욕망, 성적 가치관 등(Sexuality)에 대한 인권 중심적 접근이며, 성권리장전(Bill of Sexual Rights) 제정은 $\mathrm{IPPF}$ 의 비전과 역할의 근본이 되는 것으로 개발, 양성평등, 인간의 존엄성, 자유의 문제와도 연결되어 있음

- $\mathrm{IPPF}$ 는 성권리장전 제정을 위해 여러 지역 관 계자와 협의중이며, 이러한 지역 회의를 통해 다양한 문화와 관점의 차이를 극복하고자 노력 하고 있음

- Rabat Declaration(라바선언) : 아랍지역 성 생식보건 컨퍼런스에는 국회의원, NGOs, 청년층, 종교단체 등 다양한 관계자가 참석 하였으며, 그 결과물로 라바선언(Rabat Declaration)을 발표, SRHR이 개발에 있어 중요한 우선분야라는데 대한 인식을 함께하 였으며 이는 Advocacy의 중요한 tool로 평 가됨

- 유럽 네트워크 워크샵 : 동성애자, 트렌스젠 더 문제

- 미주지역에서의 인권 전문가 위원회 발표 등
- 이에 대해 공여국들은 동 권리장전이 UN, $\mathrm{WHO}$ 등 다른 국제기구들에서도 채택될 수 있 도록 $\mathrm{IPPF}$ 가 노력하여줄 것을 요청함

\section{55년 후의 시민사회}

- 1952년 설립 이후 초기 가족계획사업에서부터 1990년대 5A 수립, 성생식보건 서비스와 최근 성권리 개념 정립을 위한 활동까지 아우르고 있는 $\mathrm{IPPF}$ 의 모든 성과가 NGOs 및 시민사회 의 역할과 협조로 가능했다고 평가

- 이어서 IPPF는 향후 성생식보건 및 인구관련 회의들을 주관하여 NGOs 및 시민사회의 참여 를 확보하고, 지속적인 협력관계를 구축하여 갈 것을 약속함

\section{7. 공여국 피드백}

\section{- KOICA}

- KOICA는 IPPF가 아프리카지역 보건사업에 초점을 맞추는 것과 같이, 한국 역시 아프리 카 개발을 위한 이니셔티브 발표, 항공권 연 대기금 도입 등을 통해 아프리카 지역 질병 퇴치를 위해 노력하고 있음을 설명함

- 아울러 KOICA는 아프리카지역 보건분야 사 업 확대에 따라 동분야 사업 추진 역량 강화 를 위해 다자기구와의 협력관계를 강화할 수 
있는 방안 또한 모색중인바, 보건사업에 대 한 KOICA 인식의 지평이 넓어질 수 있도록 성생식보건 전문 기관인 $\mathrm{IPPF}$ 의 경험과 지 식을 지속적으로 공유하여 줄 것을 요청함

\section{- 일본}

- 국회의원 및 의사 결정자들의 관심을 이끌기 위한 IPPF의 지속적인 활동을 요청하였으 며, IPPF가 아프리카 뿐 아니라 아시아 지역 에도 초점을 맞추어 활동하여 줄 것을 희망 하면서 IPPF가 세계 성생식보건 분야 전문 $\mathrm{NGO}$ 이자 $\mathrm{UN}$ 자문기관인 점을 감안, 공여 국의 공통적 문제인 고령화 문제에 대한 $\mathrm{IPPF}$ 의 관심을 요청함

\section{- UNAIDS}

- UNAIDS는 앞으로 에이즈 예방 활동에 더 주력할 것이며, IPPC가 AIDS 환자들에 대 한 사회적 낙인을 철폐하는 등 권리에 기반 을 둔 접근(rights-based approach)을 하고 있는 점이 매우 고무적이라 평가함

\section{- 캐나다 (CIDA)}

- IPPF와는 오랜 협력관계를 구축하였으며, 성생식보건분야의 지속적인 Advocacy, 조 사 자료들이 필요하다 언급함. 성생식보건을 통합한 보건시스템 강화가 중요하며, 성권 리, 양성평등 문제를 다룬 증거기반한 사업 결과에대한 자료들을 번역, 자료를 배부할
필요가 있음을 설명함

\section{- 스웨덴 (SIDA)}

- 1992년도부터 참여한 이래, 성권리 헌장 추 진은 매우 고무적인 일이라 평가하면서 지속 적인 $\mathrm{IPPF}$ 에대한 지원을 약속함. 덴마크를 포함한 4 개국가와 함께 공적개발원조사업의 효율성을 평가한 결과 청소년 대상사업과 Advocacy 역할의 중요성을 인식하였다고 말하면서 향후 소외계층들 대상 이니셔티브 사업 개발을 요청함

\section{- 덴마크}

- 글로벌지표를 이용한 청소년 사업 분석과 성 권리 의안 추진한 깊은 인상을 표시함. 정치 적 변화가 있었으나 정부의 성생식보건 사업 에 대한 관심은 확고하며, 공여국 회의형식 을 소규모 그룹으로 추진하는 것도 성생식보 건사업을 이해하는데 도움이 될 것이라는 의 견을 제시함. 또한 생식보건을 통합하는 보 건시스템 강화에 높은 관심을 보임

\section{- 휴렛 재단}

- 기후변화와 빈곤퇴치는 지속적인 관심이 요 구됨. 향후 생식보건사업과 관련한 물품의 사용, 호르몬 등에 대하여 관심을 두고 IPPF 전략을 적용시 기후변화와 빈곤과의 관계를 파악하기 바람 


\section{- 노르웨이}

- 성생식보건의 우선순위를 애드보커시, 청소 년사업, 인공임신중절예방 등에 중점을 두고 지속적으로 활동해 줄 것을 요청함

- 환경요인을 중재한 성생식보건사업을 요구 하였으며, 에너지부문과 양성평등을 통합하 는 문제를 도전 과제로 제시함

\section{- 유럽위원회(EC)}

- 주인의식, 파트너쉽, 원조조화, 국가전략에 있어서 약속을 이끌어 내는 것을 주요 목표 로 제시하였음. 2007년에 보건전략을 설정 하면서 성생식권리, 양성평등을 정책에 통합 한 전략(2010-2030)을 설정하였으며, 총 2 억달러 관련 예산 중 86 백만달러를 현재 배 분하였다고 설명함.

\section{- 스위스}

- 인권, 성권리장전 제정의 중요성을 확인함. 시민사회를 활용한 $\mathrm{IPPF}$ 의 경험은 중요하 며, 회원협회의 역량강화, HIVAIDS 신규정 책, 생식보건을 통합한 보건시스템 강화 등 원조사업 실행에 많은 도움을 받고 있다고 설명함.

- 국제사회에서 IPPF의 발언권이 지속되기 바 라며, 이미 $\mathrm{WHO}, \mathrm{UNFPA}$ 등 관련 주요기 관과 조사 연구를 다수 실행한 것을 알고 있
는바, 이와 관련된 가이드라인, 결과보고 자 료들을 제작 배부하여 증거기반(Evidence based) 사업을 실시할 것을 건의함

\section{- 독일(BMZ)}

- IPPF 성생식보건 사업 보고에 감사하며, 지 속 지원을 약속함. 향후 예정된 국제인구개 발회의+15 (ICPD+15, 2009)에 대한 준비를 주도면밀하게 해 줄 것을 요청함

\section{- 뉴질랜드}

- 소규모로 태평양지역의 개발원조를 지속해 오고 있으며, IPPF의 경험을 계속 공유할 수 있기를 희망함

\section{- 호주}

- 청소년사업에 주력하려는 노력에 감사하며, 시민사회협력을 지속적으로 구축하여 줄 것 을 당부함

\section{- 빌게이츠멜린다 재단}

- 10 년간 6 억달러를 성생식보건사업에 지원하 였으며 2000년도에는 피임도구 보급에 중점 을 두고, RH coalition(생식보건협의체)를 지원하였음을 설명함

\section{영국}

- 범지구적으로 성생식보건 애드보커시를 확 대하여줄 것을 요청하였으며, Safe abotion 
fund 사업 발표에 사의를 표하며 지속적인 지원을 약속, 향후 5 년간 2.5 백만달러를 지 원할 것임을 공표함

\section{- Butfett 재단}

- 유엔인구기금 중앙아시아 지역대표, 덴마크 대표이기도 하였으며, 패커드 재단은 250 백 만달러를 가족계획과 안전한 인공임신중절 사업에 지원하였으며, IPPF와 협력한 사업 을 제안함. 의료서비스관리를 제공하면서 $\mathrm{IPPF}$ 의 도움과 협력이 요구됨

\section{- 핀란드}

- 환경요인을 cross cutting issue(횡적 부문 문제)로 다루어 생식보건사업과 통합할 필요 가 있다고 언급함. 2007년 600,000유로, 2008년도 800,000 유로를 지원 계획임을 공 표함

\section{- 네덜란드}

- IPPF회의는 공여기관들의 네트워크 구축에 유용한바, 국제사회에서 생식보건분야 파트 너쉽 구축을 위한 지속적인 노력 요구하였 음. 향후 3 년간 $\mathrm{IPPF}$ 를 지원할 것이며, 생식 보건물품제공, 청소년 사업, 안전한 인공임 신중절, 성권리 의안 추진, 여성권익향상을 위한 사업을 계속하기 바람.

\section{II. 보건시스템 강화와 시민사회의 역할}

\section{1. 보건시스템 강화와 성관련 보건 서비스}

- 현재 가족계획, 피임, HIV/AIDS 등 성생식관 련 보건분야는 동분야를 명기하는 국가 예산 확보 실패, 훈련된 의료 인력 부족 등으로 활동 의 효율성을 담보하지 못하고 있음

- 이로 인해 수많은 공여기관들의 기금은 관련분 야 국가개발계획에 효율적으로 통합되기 어려 울뿐 아니라, 타 공여기관과의 원조조화 (Donor Coordination) 역시 효율적으로 이루 어지지 않고 있는 실정임

- 따라서 각국이 성생식분야 관련 독자적 예산을 확보할 수 있도록 지속적으로 정책결정자를 설득하는 수직적 캠페인을 진행하는 동시에 시 민사회 및 $\mathrm{NGO}$ 와의 네트워크 구축을 통해 관 련 서비스를 제공하는 수평적 캠페인을 통합적 으로 추진하여야함

- 이러한 민관 통합 보건시스템의 모범 사례가 바로 과거 한국의 가족계획사업인바, 당시 $\mathrm{IPPF}$ 는 지속적으로 한국 정책결정자를 접촉하 여 국가 개발에 있어 가족계획의 중요성을 설 명하였으며, 한국 정부 역시 강력한 주인의식 을 가지고 경제개발 5 개년 계획에 가족계획 사 
업을 포함여 정부, 민간단체, 보건소 등 민관이 함께 동 사업을 통합적으로 추진함

- 이에 당관 이원우 참사관은 과거 한국에 대한 $\mathrm{IPPF}$ 의 가족계획사업에 사의를 표하고, 우리 나라 역시 2006년 700백만불이던 ODA 규모 를 2015년까지 32억불로 단계적으로 확대함으 로써 과거 원조수혜에 보답하기 위한 노력을 지속하고 있음을 설명함

- 또한 한국 역시 지구촌 질병퇴치 노력에 동 참하기 위해 1993년UNDP가 추진한 국제백 신연구소(IVI)를 유치, 백신 개발과 기술이전 을 주요 사업으로 추진하고 있으며, 이에 대 한 게이츠재단의 지원에 사의를 표함

\section{TICAD IV 및 G8 정상회담}

- 2008.5월 요코하마 TICAD IV 회의와 2008.7 월 홋카이도 도야코 G8 정상회담의 의제 중 하 나로 인간안보 개념에 입각한 '보건시스템 강 화' 방안이 논의되는바, 회의에 참석한 공여기 관 관계자들은 일본 정부측에 이에 대한 의견 과 제안을 전달하였음
- '보건시스템 강화' 는 기존의 질병중심적 접 근이 아닌, 시스템 구축을 위한 의료인력 확 보, 개인과 커뮤니티의 능력 강화를 포함하 는 보다 통합적 접근이며, 이를 위해 일본은 정부, 국제 $\mathrm{NGO}$, 민간기업, 학계 및 시민사 회 등 다양한 이해 당사자들의 참여를 강조 하고 있음

- 또한, IPPF, UNFPA, IOM, WHO, WB 등 보건분야 전문기구로부터 동 의제와 관련된 Policy Recommendation Document를 접 수하여 구체 의제 형성에 참고하고 있음

- 공여국들은 2000 년 G8 오키나와 정상회담시 일본이 발표한 'Okinawa Infectious Disease Initiative' 가 AIDS 퇴치를 위한 'Global Fund' 설치로 이어진 것과 같이 금번 G8 정상 회담에서도 가족보건, 모성보건 등 성생식관련 의제를 명기하여 성생식보건 관련 기금이 조성 되는데 힘을 실어주기를 희망하였으며, 포괄적 인 보건시스템 구축을 위한 시민사회의 역할 또한 특별히 언급되어지기를 희망하였음

[자료 : 주영국대사관) 